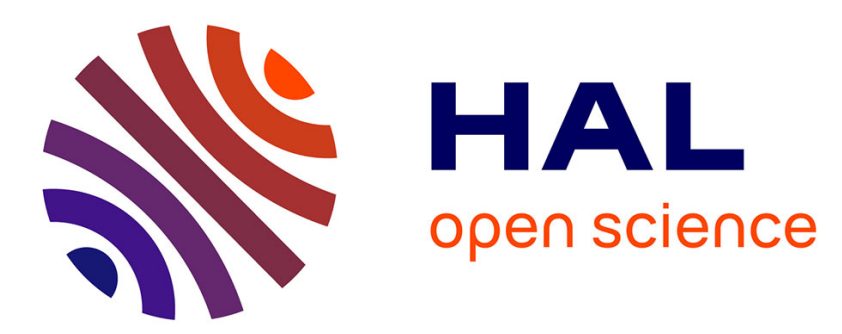

\title{
Mössbauer-Effect Study of Ca-Substituted Magnetites
}

\author{
J. Cieslak, S. Dubiel, J. Orewczyk, S. Jasienska
}

\section{To cite this version:}

J. Cieslak, S. Dubiel, J. Orewczyk, S. Jasienska. Mössbauer-Effect Study of Ca-Substituted Magnetites. Journal de Physique IV Proceedings, 1997, 07 (C1), pp.C1-589-C1-590. 10.1051/jp4:19971242 . jpa-00254928

\section{HAL Id: jpa-00254928 https://hal.science/jpa-00254928}

Submitted on 1 Jan 1997

HAL is a multi-disciplinary open access archive for the deposit and dissemination of scientific research documents, whether they are published or not. The documents may come from teaching and research institutions in France or abroad, or from public or private research centers.
L'archive ouverte pluridisciplinaire HAL, est destinée au dépôt et à la diffusion de documents scientifiques de niveau recherche, publiés ou non, émanant des établissements d'enseignement et de recherche français ou étrangers, des laboratoires publics ou privés. 


\title{
Mössbauer-Effect Study of Ca-Substituted Magnetites
}

\author{
J. Cieslak, S.M. Dubiel, J. Orewczyk* and S. Jasienska* \\ Faculty of Physics and Nuclear Techniques \\ * Faculty of Metallurgy and Material Engineering, The University of Mining and Metallurgy (AGH), al. \\ Mickiewicza 30, 30-059 Krakow, Poland
}

\begin{abstract}
Ca}_{x} \mathrm{Fe}_{3-x} \mathrm{O}_{4}$ samples, with $x \leq 0.28$, prepared from $\alpha-\mathrm{Fe}_{2} \mathrm{O}_{3}$ and $\mathrm{CaO}$ by the Bridgeman method were investigated by means of ${ }^{57} \mathrm{Fe}$ Mössbauer spectroscopy. Room temperature spectra gave evidence that the samples were multi-phase with $73 \%$ to $99 \%$ contribution of the calciomagnetite, depending on the sample. Analysis of the subspectra associated with the calciomagnetite enabled to conclude that $\mathrm{Ca}$-ions reside on the tetrahedral (A) sites and have not random distribution. They reduce the hyperfine field at Fe nuclei occupying the octahedral positions (B) by $12.3(1.0) \mathrm{kOe}$ per one Ca-ion and cause a decrease of the average hyperfine field, $\left\langle H_{B}\right\rangle / d x$ at the rate of $29 \mathrm{kOe} / \mathrm{mol} \%$ for $x \leq 0.07$ and of $387 \mathrm{kOe} / \mathrm{mol} \%$ for larger $x$. A linear correlation between $\left\langle H_{B}\right\rangle$ and the average isomer shift $\left\langle\overline{I_{B}}\right\rangle$ was revealed to hold. It permitted to conclude that Ca-doping causes a decrease of the spin-density and an increase of the charge-density at Fe nuclei occupying the B-sites of magnetite.
\end{abstract}

Magnetite, $\mathrm{Fe}_{3} \mathrm{O}_{4}$, a member of the oxide spinels family, has been a subject of numerous investigations [1]. There are two main reasons for the interest in the compound: (i) scientific and (ii) technological. The former stems from the fact that magnetite represents a classical case of the ferrimagnetic structure, on which various theoretical models depicting phase transitions as well as exchange interactions can be tested and compared. The latter is due to the fact that magnetite, a basic iron ore sinter, is important in the steel making industry.

Despite a vast body of experimental data and theoretical calculations that have been accumulated, there are still open problems related to the issue which, at least partly, stem from a large spread of data, which sometimes are at variance with each other.

A possible reason for such situation may follow from the fact that physical properties of magnetite are very sensitive to the oxygen stoichiometry [2], which in turn is a derivative of sample preparation and its history. To illustrate this let us take the results obtained by means of the Mössbauer spectroscopy only, which is a very useful tool to study ferrities. The room temperature values of the hyperfine (hf) field scatter within the interval of $480-498 \mathrm{kOe}$ for the A-site, and between $450-463 \mathrm{kOe}$ for the B-site $[3,4,5,6]$.

Substitution of $\mathrm{Fe}$-ions by other cations results in a change of the physical properties of magnetite, hence it may provide a valuable information on the subject. In addition, by doping $\mathrm{Fe}_{3} \mathrm{O}_{4}$ one can study the nature of the ion substitution which is usually selective [1]. Doping by Ca-ions, a subject of the present investigation, is also important from the technological view point as Ca-ions present in the iron ore sinters improve their sintering properties by increasing the reductibility.

Samples described here were prepared from hematite, $\alpha-\mathrm{Fe}_{2} \mathrm{O}_{3}$ and from calcium oxide, $\mathrm{CaO}$. Adequate quantities of both constituants to obtain calciomagnetitie were homogenized by mixing in an agate mortar. The mixture was next pressed under a load of $50 \mathrm{kG} / \mathrm{cm}^{2}$ into bars which were subsequently sintered at $1000^{\circ} \mathrm{C}$ for 4 to $5 \mathrm{~h}$ in air. The samples obtained were finally remelted by the Bridgeman method.

The lattice constant of the calciomagnetites, $a$ was determined by the x-ray diffraction and the real content of $\mathrm{Ca}$ in the structure, $x^{*}$ by the microprobe analysis. The latter was significantly lower than the nominal value, $x$.

The Mössbauer spectra collected at $295 \mathrm{~K}$ (for a typical ones see Fig. 1) gave a clear evidence that the samples were multi-phase. The analysis of the spectra made it possible to identify particular phases as well as to determine their relative population. For the latter it was assumed that the $f$-factor was the same for each phase present. Calciomagnetite turned out to be the dominant phase with a share of $73 \%$ to $99 \%$.

The presence of Ca-ions in the magnetite structure manifests itself in the decrease of the hf field at Fe nuclei occupying the B-sites. One Ca-ion present on the A-site reduces this field on average by $12.3(1.0) \mathrm{kOe}$. This is much less than $30 \mathrm{kOe}$ as reported in [4]. Such a behaviour of Ca-ions causes the average B-site hf field, $\left\langle H_{B}\right\rangle$ to decrease with $x^{*}$. 
Also the average isomer shift of Fe nuclei on the B-sites, $\left\langle I_{B}\right\rangle$ exhibits similar dependence on $x^{*}$, as $\left\langle H_{B}\right\rangle$ does, indicating thereby that their charge-density is affected by the substitution. There is a nice linear correlation between $\left\langle H_{B}\right\rangle$ and $\left\langle I_{B}\right\rangle$ as shown in Fig. 2. Its slope is equal to $584 \mathrm{kOe} / \mathrm{mm} / \mathrm{s}$ and the correlation coefficient $\mathrm{r}=0.95$. The decrease of $\left\langle H_{B}\right\rangle$ and $\left\langle I_{B}\right\rangle$ with $x^{*}$ means that there is an effective charge transfer from Fe nuclei on B-sites caused by the Ca-substitution. Taking into account that the difference of $0.4 \mathrm{~mm} / \mathrm{s}$ between $I_{A}$ and $I_{B}$ is associated with the difference of 0.5 electrons, one can estimate the maximum charge transfer for $\approx 0.07$ electrons in the case of the most concentrated calciomagnetite. The spectral parameters of Fe nuclei sitting on the A-sites are independent of $\mathrm{Ca}$ content. This can be taken as evidence that the exchange integral $J_{A-A}$ is vanishingly small. This supports some theoretical calculations [7] but is at variance with other results $[8,9]$.
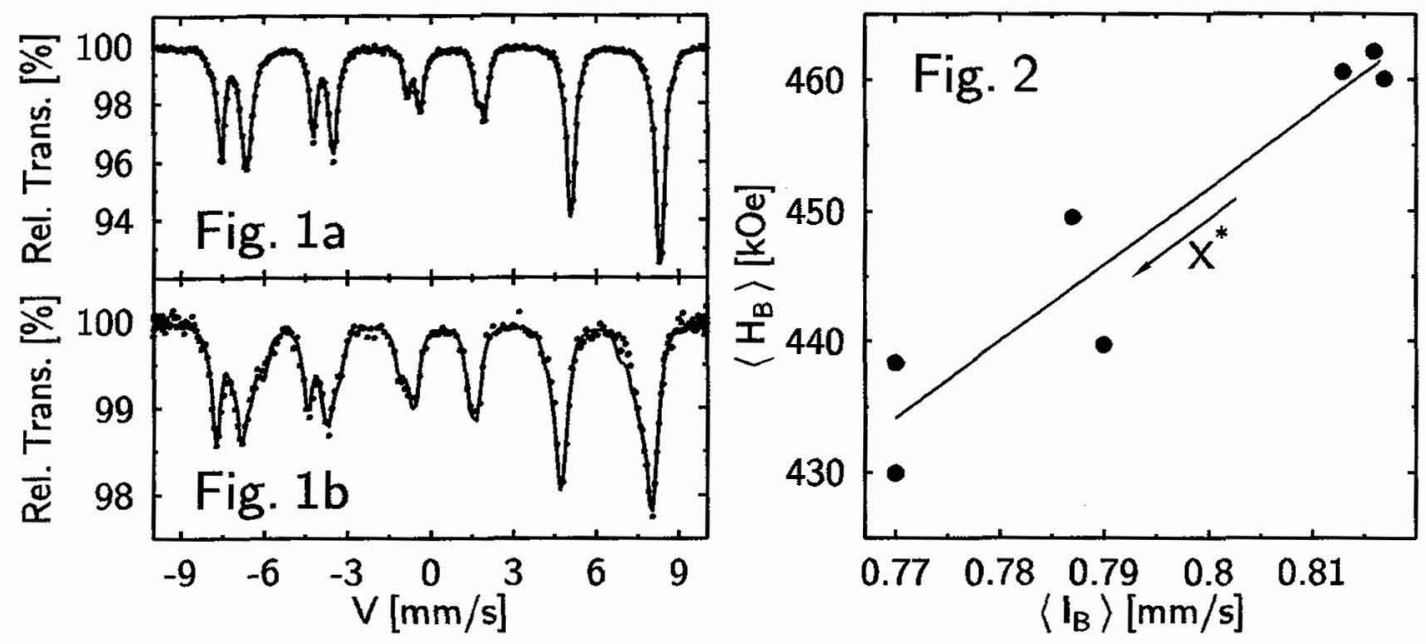

Fig. 1: ${ }^{57} \mathrm{Fe}$ Mössbauer spectra of $\mathrm{Ca}_{x} \mathrm{Fe}_{3-x} \mathrm{O}_{4}$ recorded at $295 \mathrm{~K}$ for (a) $x^{*}=0.07$ and (b) $x^{*}=0.12$.

Fig. 2: The average hf field, $\left\langle H_{B}\right\rangle$ as the function of the average isomer shift, $\left\langle I_{B}\right\rangle$. The stright line is the best fit to the data and has a slope of $587 \mathrm{kOe} / \mathrm{mm} / \mathrm{s}$. The arrow shows the direction in which $x$ increases.

Analysis of the spectra also permitted to conclude that Ca-ions substitute for the A-site exclusively, which agrees with previous conclusions $[4,5,6]$, too. However, in addition to the previous works, the present analysis (i) gives a clear evidence that the distribution of Ca-ions among the A-sites is not random, and (ii) it supplies the value of the shift of the B-site hf field due to one Ca-ion on the A-site $\Delta H=-12.3(1.0) \mathrm{kOe}$.

\section{Acknowledgements}

The investigation was in part supported by the State Research Committee (KBN) within the project No. PB 1644/3/91

\section{References}

[1] S. Krupička and P. Novak, in: Ferromagnetic Materials, vol.3, Ed. E. P. Wolfarth, North-Holland Publishing Company, 1982 , p.189

[2] Z. Kąkol, J. Sabol, J. Stickler and J. M. Honig, Phys. Rev. B, 46, 1975 (1992)

[3] E. De Grave, R.M. Persoons, R.E. Vandenberghe and P.M.A. de Bakker, Phys. Rev. B, 47, 5881 (1993)

[4] J. De Sitter,A. Govaert, E. De Grave, D. Chambaere and G. Robbrecht, Phys. Stat. Sol. (a), 43, 619 (1977)

[5] A. Z. Hrynkiewicz, D. S. Kulgawczuk, E. S. Mazanek, A. J. Pustówka, J. A. Sawicki and M. E. Wyderko, Phys. Stat. Sol. (b), 43, 401 (1971)

[6] R. Gérardin, A. Bonazebi, E. Millon, J. F. Brice, O. Evrard, and J. P. Sanchez, J. Sol. Stat. Chem., 78, 154 (1989)

[7] M. Uhl and B. Silberchicot, J. Phys. Condens. Matter, 7, 4227 (1995)

[8] Groupe de Diffusion Inélastique des Neutrons, J. Phys. C, 1, 1182 (1971)

[9] K. T. Möglestue, IAEA Congress of Copenhagen, 2, 117 (1968) 